\title{
Evaluation of the morphological characteristic and sex differences of sternum by multi-detector computed tomography
}

\author{
S. Ateşoğlu, M. Deniz, A.i. Uslu \\ Department of Anatomy, Faculty of Medicine, Harran University, Şanliurfa, Turkey \\ [Received: 25 August 2017; Accepted: 11 October 2017]
}

\begin{abstract}
Background: Sternum is one of the skeleton parts which have frequently congenital anomalies and variations are commonly used by researchers in determining sex. We evaluated the morphological characteristics and sex-related changes of the sternum in adult individuals using multidetector computed tomography in our study.
\end{abstract}

Materials and methods: Two hundred adults (103 female and 97 male) aged between 18 and 87 years were evaluated. Utilising the morphological characteristics of the sternum based on the multislice images; length, width and the thickness of manubrium, length, width and the thickness of corpus sterni, total length of sternum, sternal angle, sternal index (SI), length of the xiphoid process, the thickness of xiphoid process, the number of indents of xiphoid process were measured and a total of 20 parameters were evaluated by adding age, height and weight to these variables.

Results: The mean length of the manubrium, the length of corpus sterni, the length of total sternum, SI, sternal angle were found in females $46.7 \pm 5.1$, $86.6 \pm 9.7,133.1 \pm 1.1,54.47 \pm 10.0$ and $163.75 \pm 5.79$; in males $51.2 \pm 6$, $102.4 \pm 13.3,154.1 \pm 13.1,50.11 \pm 10.02$ and $162.21 \pm 6.17$, respectively. We found that Hyrtl's Law and SI did not provide adequate accuracy for sex determination in our patients. It has been detected that the length of the manubrium alone is not helpful for individual samples. Total length of the sternum was found to be more reliable than the length of the manubrium and the length of corpus sterni. We determined sternal cleft and sternal foramen as $0.5 \%$ and $3.5 \%$, respectively. Conclusions: We suggest that the morphometric standards cannot be universally applied and can demonstrate individual differences. The standard rules must be implemented for every population. (Folia Morphol 2018; 77, 3: 489-497)

Key words: sternum, morphometric analysis, sex, sternal variations, multidetector computed tomography

\section{INTRODUCTION}

The sternum is a flat bone situated vertically in the median and the anterior part of the thoracic cage. Sternal morphological measurement is greatly important in anthropological research, clinical, and surgical approach. The largest series evaluating the sternal morphometric analysis, sternal variations and anomalies were based on the macroscopic and

Address for correspondence: M. Deniz, PhD, Department of Anatomy, Faculty of Medicine, Harran University, 63300 Şanliurfa, Turkey, tel: + 90414 3181370, fax: + 90414 3181370, e-mail: denizmf@hotmail.com 
radiographic appearances of the sternum in autopsy populations [5, 19, 25-27]. Sternal variations and anomalies represent congenital anatomic defects, occurring as a result of an impaired and incomplete ossification centre fusion $[8,13]$. The frequencies of sternal variations in living subjects have been described based on their radiograph, helical computed tomography (CT) or magnetic resonance imaging (MRI) appearances $[1,23,30]$. Sexual dimorphism of the sternum was first described by Wenzel [28]. A century later, both Dwight [11] and Hyrtl [16] conducted similar tests on the sternum and recognised the pattern of $1: 2$ ratio in females and $2: 1$ ratio in males. The manubrium of the female sternum exceeds half the length of the body, while the body of the male sternum is, at least, twice as long as the manubrium [12]. Paterson [22] recorded that sternal body was longer and narrower in males than in females. For sexing the European sternum, Ashley [3] formulated "the 149 rule", according to which a male sternum exceeded $149 \mathrm{~mm}$ in length, whereas the female sternum was less than $149 \mathrm{~mm}$. Jit et al. [18] successfully applied "the 136 rule" derived by Ashley for East African population on the North Indian population, and Dahiphale et al. [9] formulated "the 129 rule" for Marathwada region in India. Rother et al. [25] Used discriminant function analysis based on length, breadth, and thickness of sternum for sex determination successfully. Hunnargi et al. [15] applied "the 50 rule" for the manubrium confirmed sex in $77.3 \%$ male and $77.5 \%$ female. This law continues to be taught as true, regardless of the many studies that found it to be unreliable $[9,15,18]$. Additionally, Bongiovanni et al. [7] tested, sexual dimorphism of the sternum between American black and American white populations that were in agreement with previous studies while the mean values of sternal index (SI) conform to Hyrtl's Law, the range of values largely overlap, and prove unreliable for sex estimation. The standardisation according to shape was present in one standard sternal shape present in more than second/third of the analysed samples of both sexes [26].

Recently, an increasing use of multidetector CT (MDCT), the sternal morphometric analysis and variations can be identified more frequently $[1,4,10,30]$. The aim of this study was to investigate morphometric analysis, sexual dimorphism, sternal variations and sternal anomalies in MDCT imagines.

\section{MATERIALS AND METHODS}

The study was performed on 200 subjects aged 18-87 years (103 female, 97 male) who underwent thorax MDCT examination. Ethics approval was obtained from the Ethics Committee of the Medical School of Harran University. After excluding patients with sternal deformity, a history of thoracic trauma or surgery, sternal mass, or infiltration morphometric measurements of the sternum were carried out on MDCT images (Fig. 1A-D).

The 10 measurements and 3 indices defined in the literature were used in the study [17, 24]:

- length of manubrium (M): distance between the midpoint of incisura jugularis and midpoint of the manubriosternal joint;

- width of manubrium (MW): the distance between the right and the left midpoint of incisura costalis;

- length of corpus sterni (B): distance between the midpoint of manubriosternal joint and xiphisternal joint;

— width of corpus sterni (CSW):

- incisura costales 2-3 (CSWa): the distance between the right and the left midpoint of incisura costales 2-3;

- incisura costales 3-4 (CSWb): the distance between the right and the left midpoint of incisura costales 3-4;

- incisura costales 4-5 (CSWc): the distance between the right and the left midpoint of incisura costales 4-5;

- maximum thickness of manubrium: the biggest thickness at the level of the central point of the binding clavicular notch and from the central longitudinal line junction;

- minimum thickness of manubrium: the minimum thickness from the point of junction in the central longitudinal line in the middle of the manubrium;

- the thickness of corpus sterni: while the sternum was fixed in the left lateral position at two points were measured. Point 1: the distance between 2 and 3 sternabra;

- the length of totality sternum (CL): sum of $M$ and $B$ $(\mathrm{M}+\mathrm{B})$;

- the length of xiphoid process: the distance between articulation sternoxiphoidea and ending xiphoid process;

- the thickness of xiphoid process: the thickest point of the distance between articulation sternoxiphoidea and ending xiphoid process; 

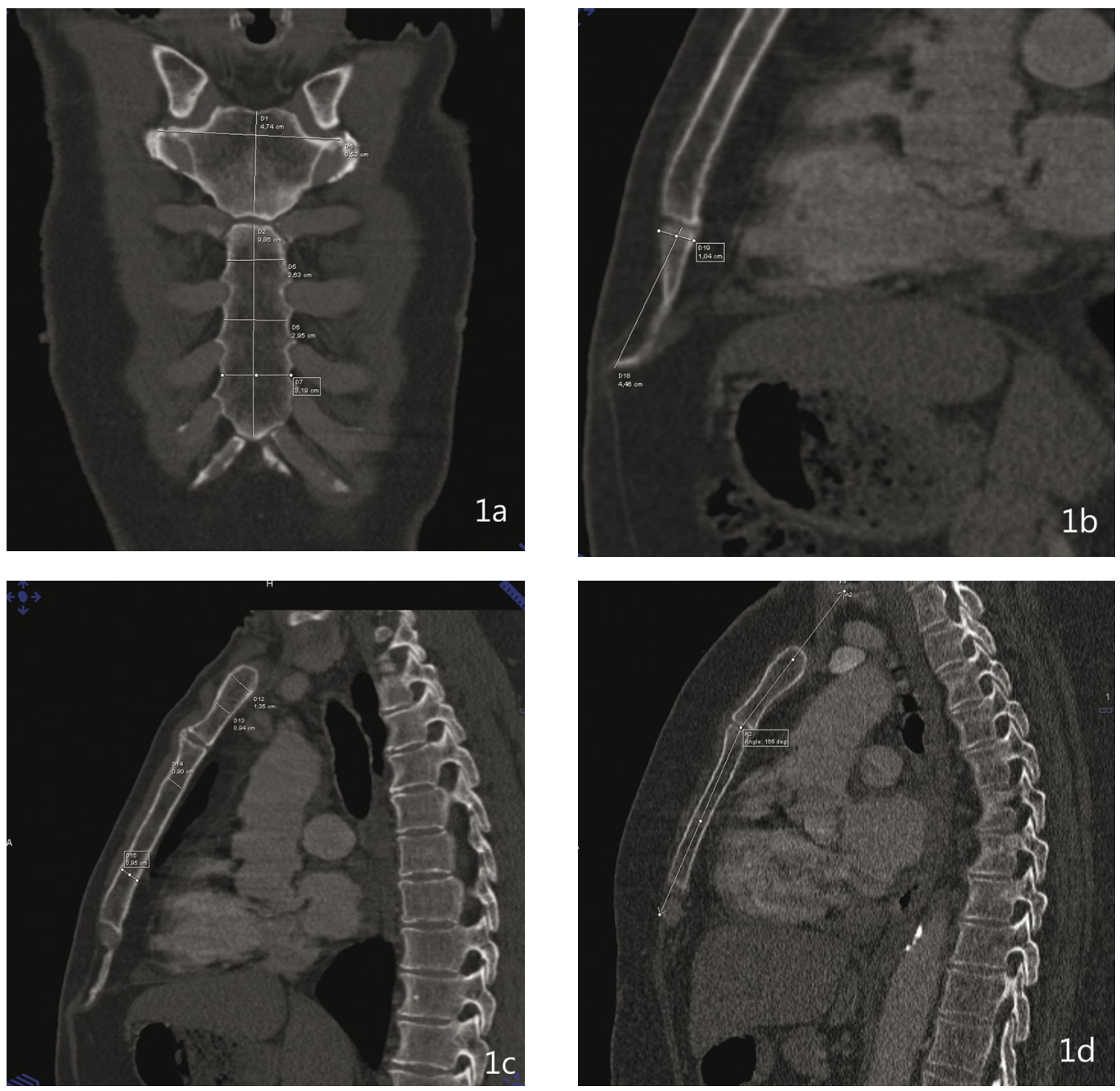

Figure 1. Measurements of sternum performed on multislice computed tomography images. A. Length and width of manubrium and corpus sterni; B. Length of xiphoid process; C. Thickness of manubrium and the corpus sterni; D. Sternal angle.

- sternal angle: the sternum was fixed in the left lateral position. A line was drawn a parallel to manubrium as passing in the middle of incisura jugularis. And crossing this line as passing in the middle of the corpus sterni a parallel line was drawn. Sternal angle was determined by measuring the angle between two lines.

- sternal index (SI): it is the division of $\mathrm{M}$ by $\mathrm{B}$, then multiplied by 100 [(M/B) $\times 100]$.

MDCT imaging was performed with a four-detector row CT scanner (Somatom Sensation 4, Siemens Medical Solutions). The common scanning parameters for all patients were as follows: $120 \mathrm{kVp}$, $90 \mathrm{mAs}, 0.5-\mathrm{sec}$ gantry rotation, $4 \times 2.5 \mathrm{~mm}$ collimation, and a pitch of $6(4 \times 1.5), 30-\mathrm{mm} / \mathrm{sec}$ table feed, and 2-mm axial and 3-mm multiplanar reconstruction image thicknesses. Analyses of the image data were based on axial and reformatted images. While measuring, each subject was given a standing position as head to be upright and hands to be on both sides. The frequencies of the sternal foramen (round defect in the lower third of the sternum), sternal cleft (congenital vertical defect of the sternum, types of the xiphoidal ending (absence; single, double, or triple ending) were detected. In order to define sexual dimorphism of sternum maximum value for female and minimum value for the male of the length of the manubrium, corpus sterni, and total sternum collected and the averages were calculated. According to the results, a rule was identified for each parameter. In analysing the data descriptive statistics, that consist of minimum, maximum, mean, and standard deviation, and in independent samples $t$ test for univari- 
ate analysis, Pearson correlation analysis to show that the change in the two continuous variables was used. Statistical analysis was performed using SPSS 11.5 software.

\section{RESULTS}

The mean age of males and females was $45.22 \pm$ \pm 17.99 and $50.49 \pm 16.92$ years, respectively. The mean length of the manubrium for female and male was $46.7 \pm 5.1 \mathrm{~mm}$ and $51.2 \pm 6 \mathrm{~mm}$, respectively. The mean length of the corpus sterni for female and male was $86.6 \pm 9.7 \mathrm{~mm}$ and $102.4 \pm 13.3 \mathrm{~mm}$, respectively. The mean length of the total sternum for female and male was $133.1 \pm 11 \mathrm{~mm}$ and $154.1 \pm$ $\pm 13.1 \mathrm{~mm}$, respectively. The SI was found for female and male $54.47 \pm 10.00 \mathrm{~mm}$ and $50.11 \pm 10.02 \mathrm{~mm}$, respectively. The sternal angle was found for female and male $163.75 \pm 5.79$ and $162.21 \pm 6.17$, respectively. The mean thickness of the manubrium for female and male was found $8 \pm 1.6 \mathrm{~mm}$ and $9.2 \pm$ $\pm 1.5 \mathrm{~mm}$, respectively. The thickness of corpus sterni between 2 and 3,4 and 5 sternabra in female and male was found $8.1 \pm 1.3 \mathrm{~mm}$ and $9.2 \pm 1.5 \mathrm{~mm}$, $7.9 \pm 1.5 \mathrm{~mm}$ and $8.5 \pm 1.5 \mathrm{~mm}$, respectively. The width of manubrium for female and male was found $54.6 \pm 5.2 \mathrm{~mm}$ and $64.4 \pm 7 \mathrm{~mm}$, respectively. The width of corpus sterni between 2 and 3 , between 3 and 4 , between 4 and 5 sternabra in female and male, $23.8 \pm 3.3 \mathrm{~mm}$ and $27.7 \pm 4.1 \mathrm{~mm}$, $25.8 \pm 3.8 \mathrm{~mm}$ and $30 \pm 4.5 \mathrm{~mm}, 27.8 \pm 4.7 \mathrm{~mm}$ and $32.4 \pm 6 \mathrm{~mm}$, respectively. The length of a xiphoid process for female and male was found $29 \pm 10 \mathrm{~mm}$ and $39.1 \pm 11.3 \mathrm{~mm}$, respectively. The thickness of xiphoid process for female and male was found $6 \pm 1.3 \mathrm{~mm}$ and $6.6 \pm 1.6 \mathrm{~mm}$, respectively. Sternal morphometric measurements are presented in Table 1.

In determining gender, a rule for length of manubrium was found "52". According to this rule, the accuracy rate was found in female and male as $16.5 \%$ and $62.88 \%$, respectively.

For the length of corpus sterni, the rule was found "77". According to this rule, accuracy rate was detected for female and male $16.5 \%, 97.99 \%$, respectively. For the length of total sternum, the rule was found at 144 . According to this rule, accuracy rate was detected for female and male $85.42 \%$ and $80.41 \%$, respectively.

As a rule for the $\mathrm{Sl}$, it was found to be " 54 ". According to this rule, accuracy rate was determined for female and male $55.3 \%$ and $63.9 \%$, respectively (Table 2). As a result of this, applicability rate of "Hyrtl rule" was found in female and male 67.0 and 50.5 , respectively.

The length of xiphoid process was found in the female and male as $29 \pm 10 \mathrm{~mm}$ and $39.1 \pm 11.3 \mathrm{~mm}$, respectively. Single, double and triple xyphoidal ending was detected in $71 \%, 10.52 \%$, and $0.5 \%$, respectively (Fig. 2).

All found sternal foramen were located in the typical position at the $1 / 3$ caudal parts of the corpus sterni. The prevalence of a sternal foramen in this sample was $3.5 \%$ (Fig. 3).

The frequency of sternal cleft was found at $0.5 \%$. And all of them were located at the manubrium (Fig. 4).

\section{DISCUSSION}

The sternum is a flat bone situated vertically in the median and the anterior part of the thoracic cage. Sternum is embryologically developed from the chondrification of the bilateral sternal plates. The sternal bone ossification is accomplished by endochondral ossification, a procedure regulated from specific ossification centres. Ossification is conducted along specific segments in the mesosternum, known as sternebrae [6]. Sternal ossification begins at fifth month of prenatal life. The ossification centres at each segment of the sternal body generally fuse to form single ossification centre during 6 to 12 years of age. The calcification and fusion of sternal body segments is usually complete by 25 years of age. Failure in this developmental process results in sternal variations and anomalies $[8,13,20,30]$.

Sternum has a great clinical significance, considering that median sternotomy is the most common surgical approach. The sternum is one of the skeleton parts with frequent variation in appearances on images or autopsy series. In living subjects, sternal variations are frequently detected incidentally on cross-sectional images. Radiologists and pathologists should be aware of the existences of these anatomical variations of the sternum as well as be familiar with their imaging features, in order to avoid diagnosis uncertainties $[4,30]$.

In our study, morphometric analysis of breadth, length, thickness and sternal angle of the sternum was performed in MDCT. The mean thickness of manubrium for female and male was found $8 \pm$ $\pm 1.6 \mathrm{~mm}$ and $9.2 \pm 1.5 \mathrm{~mm}$, respectively. The thickness of corpus sterni between 2 and 3 , between 
Table 1. Sternal morphometric measurements

\begin{tabular}{|c|c|c|c|c|c|c|}
\hline Measurements [mm] & Sex & $\mathbf{N}$ & Minimum-Maximum & $\begin{array}{l}\text { Mean } \pm \text { standard } \\
\text { deviation }\end{array}$ & $\mathbf{t}$ & $\mathbf{p}$ \\
\hline \multirow[t]{2}{*}{ The length of manubrium } & Female & 103 & $35.1-63.9$ & $46.7 \pm 5.1$ & -5.59 & 0.00 \\
\hline & Male & 97 & $39.7-71.1$ & $51.2 \pm 6$ & & \\
\hline \multirow[t]{2}{*}{ The length of corpus sterni } & Female & 103 & $55.5-108.9$ & $86.6 \pm 9.7$ & -9.56 & 0.00 \\
\hline & Male & 97 & $44.9-133.1$ & $102.4 \pm 13.3$ & & \\
\hline \multirow[t]{2}{*}{ The length of total sternum } & Female & 103 & $110.3-164.3$ & $133.1 \pm 11$ & -12.24 & 0.00 \\
\hline & Male & 97 & $124.3-187.8$ & $154.1 \pm 13.1$ & & \\
\hline \multirow[t]{2}{*}{ Sternal index } & Female & 103 & $24.11-98.73$ & $54.47 \pm 10.00$ & 3.08 & 0.00 \\
\hline & Male & 97 & $7.86-79.07$ & $50.11 \pm 10.02$ & & \\
\hline \multirow[t]{2}{*}{ Sternal angle } & Female & 103 & 148-178 & $163.75 \pm 5.79$ & 1.82 & 0.07 \\
\hline & Male & 97 & $145-176$ & $162.21 \pm 6.17$ & & \\
\hline \multirow[t]{2}{*}{ Maximum thickness of manubrium } & Female & 103 & $9.1-19$ & $12.7 \pm 2.1$ & -7.00 & 0.00 \\
\hline & Male & 97 & $10.9-19.6$ & $14.7 \pm 1.9$ & & \\
\hline \multirow[t]{2}{*}{ Minimum thickness of manubrium } & Female & 103 & $4.6-12.2$ & $8 \pm 1.6$ & -5.38 & 0.00 \\
\hline & Male & 97 & $5.1-13.0$ & $9.2 \pm 1.5$ & & \\
\hline \multirow[t]{2}{*}{ The thickness of corpus sterni 2-3 sternabra } & Female & 103 & $5.5-11.2$ & $8.1 \pm 1.3$ & -5.04 & 0.00 \\
\hline & Male & 97 & $6.4-13.1$ & $9.2 \pm 1.5$ & & \\
\hline \multirow[t]{2}{*}{ The thickness of corpus sterni $4-5$ sternabra } & Female & 103 & $4.9-12.4$ & $7.9 \pm 1.5$ & -3.02 & 0.00 \\
\hline & Male & 97 & $4.2-13.1$ & $8.5 \pm 1.5$ & & \\
\hline \multirow[t]{2}{*}{ Width of manubrium } & Female & 103 & $41.5-74$ & $54.6 \pm 5.2$ & -11.18 & 0.00 \\
\hline & Male & 97 & $45.6-80.3$ & $64.4 \pm 7$ & & \\
\hline \multirow[t]{2}{*}{ Width of corpus sterni 2-3 sternabra } & Female & 103 & $17-34$ & $23.8 \pm 3.3$ & -7.34 & 0.00 \\
\hline & Male & 97 & 19-38 & $27.7 \pm 4.1$ & & \\
\hline \multirow[t]{2}{*}{ Width of corpus sterni 3-4 sternabra } & Female & 103 & $17.2-38$ & $25.8 \pm 3.8$ & -7.04 & 0.00 \\
\hline & Male & 97 & $20.4-45.6$ & $30 \pm 4.5$ & & \\
\hline \multirow[t]{2}{*}{ Width of corpus sterni 4-5 sternabra } & Female & 103 & $20.2-41.5$ & $27.8 \pm 4.7$ & -5.92 & 0.00 \\
\hline & Male & 97 & $11.0-48.2$ & $32.4 \pm 6$ & & \\
\hline \multirow[t]{2}{*}{ The length of xiphoid process } & Female & 103 & $4.8-52$ & $29 \pm 10$ & -6.63 & 0.00 \\
\hline & Male & 97 & $8.4-65$ & $39.1 \pm 11.3$ & & \\
\hline \multirow[t]{2}{*}{ The thickness of xiphoid process } & Female & 103 & $3.1-9.6$ & $6 \pm 1.3$ & -3.07 & 0.00 \\
\hline & Male & 97 & $3.9-16.5$ & $6.6 \pm 1.6$ & & \\
\hline
\end{tabular}

Table 2. The rules and applicability rates of morphometric measurements of sternum

\begin{tabular}{lccc}
\hline Measurements & Rule & \multicolumn{2}{c}{ Accuracy rate [\%] } \\
\cline { 3 - 4 } & & Female & Male \\
\hline The length of manubrium & 52 & 16.5 & 62.88 \\
The length of corpus sterni & 77 & 16.5 & 97.9 \\
The length of total sternum & 144 & 85.42 & 80.41 \\
Sternal index & 54 & 55.3 & 63.9 \\
\hline
\end{tabular}

4 and 5 sternabra in female and male was found $8.1 \pm 1.3 \mathrm{~mm}$ and $9.2 \pm 1.5 \mathrm{~mm}, 7.9 \pm 1.5 \mathrm{~mm}$ and $8.5 \pm 1.5 \mathrm{~mm}$, respectively. Serious compli- cations after a sternal puncture for bone marrow biopsy or acupuncture have been reported in the literature- Fatal cardiac tamponade resulting from a congenital sternal foramen located in the inferior part of the sternum and the thin sternal body was seen during the sternal puncture. Therefore, the awareness of the presence of sternal variations and anomalies is important to prevent these fatal complications during bone marrow aspiration. Sternal thickness is very important in cases where bone marrow aspiration is done for diagnostic purposes. Morphology of the xiphoid process, the smallest part of the sternum, might demonstrate significant 


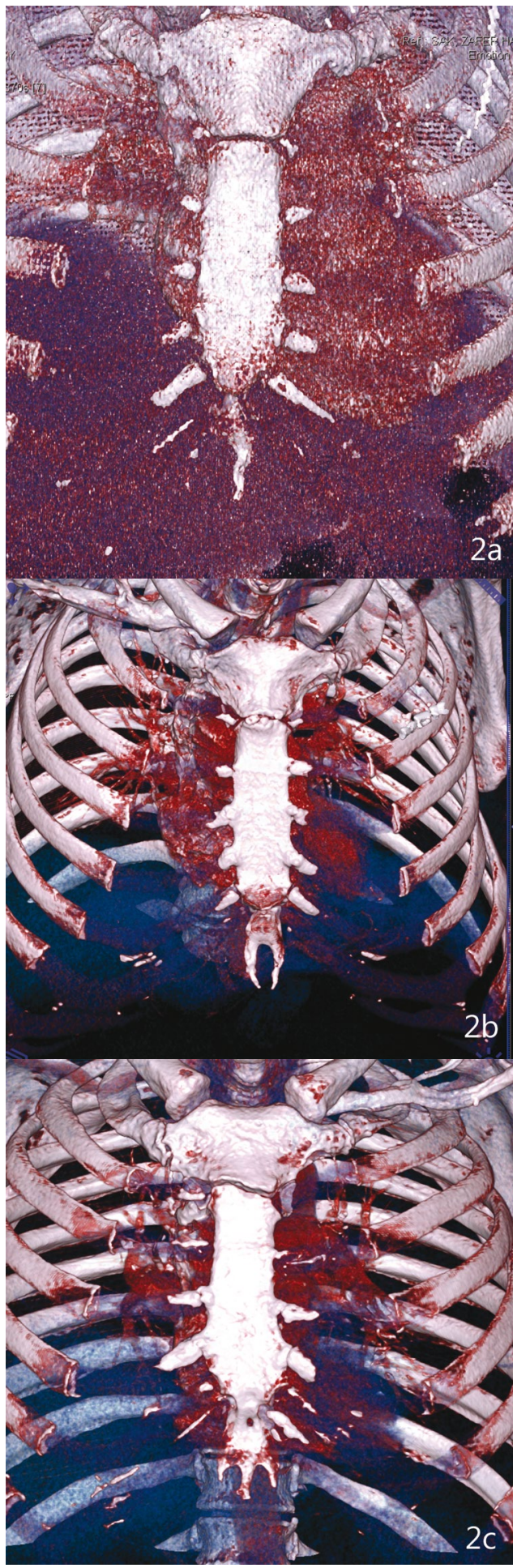

Figure 2. Multislice computed tomography images of types of xiphoidal ending. A. Single; B. Double; C. Triple.

interindividual variations although it is presented in anatomy textbooks to be a flat and totally ossified single ending bone. The xiphoid process is included in the sectional imaging of thoracic and abdominal regions during daily radiology routine and its varia-

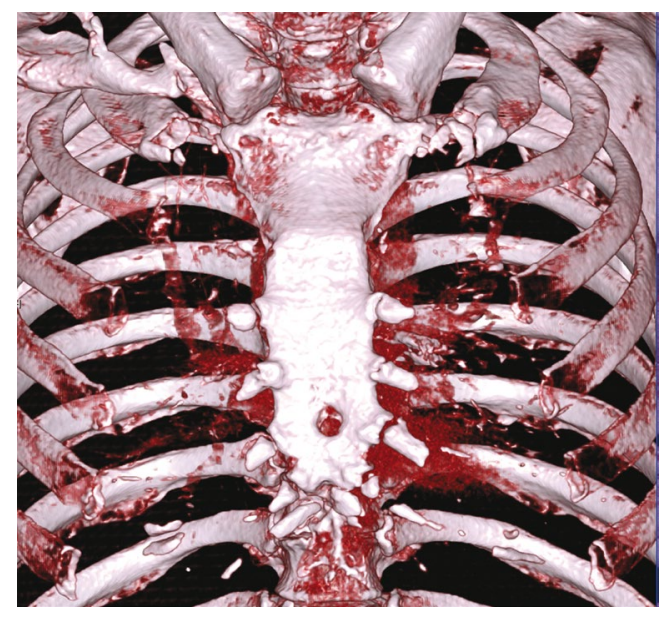

Figure 3. Multislice computed tomography image of sternal foramen.

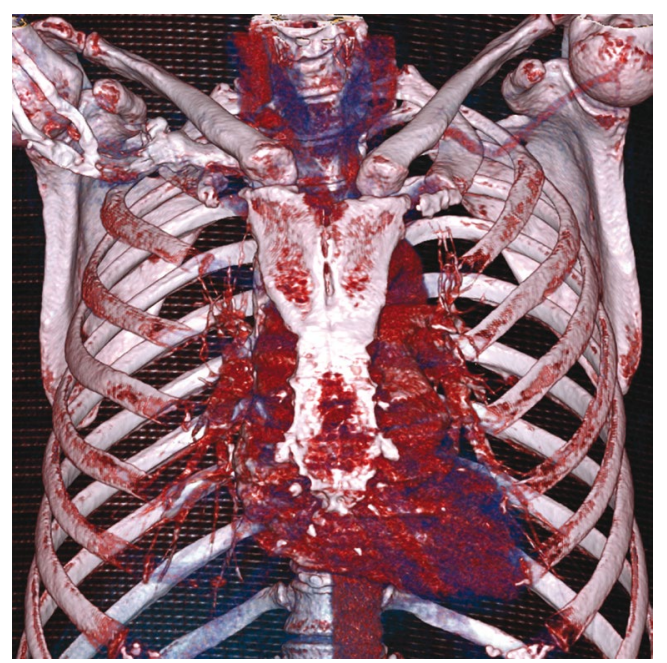

Figure 4. Multislice computed tomography image of sternal cleft.

tions might be detected incidentally. Studies in the literature are mainly based on autopsy series. There are studies in radiology the literature evaluating the variations of the sternum and its parts with direct radiography, CT, and MRI. Akin et al. [1] studied inter-individual variations of the xiphoid process in a wide adult group using 64-row MDCT. They found that the mean length and the thickness of xiphoid process had been $50 \mathrm{~mm}$ and $7.3 \mathrm{~mm}$, respectively. In our study, the length and the thickness of xiphoid process for female and male were $29 \pm 10 \mathrm{~mm}$ and $39.1 \pm 11.3 \mathrm{~mm}, 6 \pm 1.3 \mathrm{~mm}$ and $6.6 \pm 1.6 \mathrm{~mm}$, respectively. In our opinion, in part, these different results might originate from the difficulties in the visualisation of the cartilaginous portion of the xiphoid process or its differentiation from neighbouring soft tissue structures. Xiphoidal endings may 
show anatomical variations between individuals. These variable morphologies are important, because they may be mistaken for fractures during imaging. Using multislice CT in our study we have determined that there were three types of xiphoidal endings: a single $(71 \%)$, double $(10.52 \%)$, or triple $(0.5 \%)$ end of the xiphoid process. Sternal angle was found in female and male $163.75 \pm 5.79,162.21 \pm 6.17$, respectively. The difference of "1.54" degrees between female and male was not found statistically significant $(p>0.05)$.

Sex determination from skeletal remains is utmost importance in creating the biological profile of an adult individual. Traditionally, forensic anthropologists rely primarily on methods of sex assessment based on analyses of the pelvis and skull, which are considered to be highly accurate and relying heavily on these two areas within a forensic context is limiting, because they are subject to trauma, prone to taphonomic processes, or may not be present. Moreover, the skull has been proven to be less accurate than previously believed, achieving lower accuracy rates than postcranial elements using metric analyses. Therefore, alternative elements of the skeleton need to be investigated as potential indicators of sex [7].

Many researchers have used the sternum in age and sex determination. And the results of morphometric analysis have described a rule of its relevance to the population. However, some researchers have shown that there were overlapping between sexes. And have advocated this rule was not useful and reliable for individual measurements [7]. Sexual dimorphism of the sternum was first described by Wenzel [28], dates to the late $18^{\text {th }}$ century. Wenzel [28] compared the ratio between the lengths of the manubrium and corpus sterni of males and females. A century later, both Dwight [11] and Hyrtl [16] conducted similar tests on the sternum and recognised the pattern of a $1 / 2$ ratio in females and $2 / 1$ ratio in males $[11,12,16]$. This discovery prompted the creation of Hyrtl's Law, which states, the manubrium of the female sternum exceeds half the length of the body, while the body of the male sternum is, at least, twice as long as the manubrium. For sexing the European sternum, Ashley [3], formulated "the 149 rule", according to which a male sternum exceeded $149 \mathrm{~mm}$ in length, whereas the female sternum was less than $149 \mathrm{~mm}$. Jit et al. [18] successfully applied "the 136 rule" derived by Ashley for East
African population on the North Indian population and Dahiphale et al. [9] formulated "the 129 rule" for Marathwada region in India. Hunnargi et al. [15] formulated "the 131 rule" for west India population; Ramadan et al. [24] formulated "the 142" rule for the Anatolian population. In our study, we found "144 rule" in the South Eastern Anatolian Region. According to this rule, the total sternum with length above $144 \mathrm{~mm}$ was defined as male, and with a length less than $144 \mathrm{~mm}$ was defined as female. We found that of all the parameters studied $\mathrm{SI}$, the length of manubrium and corpus sternum is not exclusive enough, the total length of the sternum is a more reliable parameter in determining the sex of the sternum. We found that application rate of Hyrtl rule for female and male was 67.0 and 50.5, respectively (Table 2). According to our study, the Hyrtl rule cannot be applied for the South Eastern Anatolia population in sex determination. Similarly, Dwight [11], Ashley [3], Jit et al. [18], Dahiphale et al. [9], Hunnargi et al. [15], and Ramadan et al. [24] determined in their studies that this rule was not reliable for their populations. In a study carried out on morphometric studies of $X$ rays of the sternum, sex determination of a sufficient certainty was possible using the measurement of length and breadth obtained from X-rays of the human sternum, if a wide range of dispersion is given. The given relations and formula are valid only when measuring the sternum of adults [27]. The length of the manubrium was not found to be useful in sexual dimorphism of the sternum [21]. Some studies have emphasized that the sex determination accuracy can be increased when fourth rib measurements and the rib mineralisation pattern are taken into account in addition to sternal data [17, 24].

Radiologists and pathologists should be aware of the existences of these anatomical variations of the sternum as well as be familiar with their imaging features, in order to avoid diagnosis uncertainties $[4,30]$. Sternal clefts could be misinterpreted as a traumatic fracture, whereas a sternal foramen can be mistakenly suggested as an osteolytic lesion [4]. It may be an isolated malformation or may be accompanied by displacement of the heart or other midline abnormalities [2]. The awareness of a sternal foramen is important in acupuncture practice and sternal marrow aspiration because of the danger of heart damage $[4,30]$. Quantitative studies on the sternal foramen frequency were performed in adult patients through a roentgenograms [29]. In 
our study, sternal foramen was found in 7 (3.5\%) subjects; the foramina were all located in the inferior part of the sternal body. Moore et al. [19] detected 135 (6.6\%) sternal foramina from 2016 radiographs in an autopsy population. In Yekeler's et al. study [30], the percentage of a sternal foramen detected in the subjects were slightly higher (6.7\%) than the Stark's study result (4.3\%). In our study, none of the subjects had a foramen in the manubrium. Babinski et al. [5] reported a higher prevalence of $16.6 \%$. Akin et al. [1] determined that xiphoidal foramen was present in 216 (43.2\%) patients; 171 (34.2\%) patients had only one foramen; $31(6.2 \%)$ patients had two, 7 (1.4\%) patients had three, and $7(1.4 \%)$ patients had four or more xiphoidal foramina. Prevalence of sternal foramen features an important correlation with the sex. Most recent data indicate a male:female ratio $4: 1$ among the subjects featuring a sternal foramen [14]. The sternal foramina are developmental anomalies because of incomplete fusion of ossification centres; most often they are located in the inferior parts of the sternal body [2]. It is difficult to visualise sternal variations and anomalies by radiography. Therefore, cross-sectional imaging such as $C T$ and MRI is generally required to describe the findings detected on radiography and to reveal the additional minor changes. Multiplanar reconstructed MDCT images were helpful in wholly revealing sternal anatomy. Curved-planar coronal multiplanar reconstruction images nicely showed manubriosternal and sternoxiphoidal fusions, sternal bands and clefts, sternal and xiphoidal foramina, the types of xiphoidal ending, and xiphoidal ossification [2]. In addition, a sternal foramen is quite a frequent variant anatomy with the risk of serious complications such as pneumothorax or pericardial tamponade during sternal biopsy or acupuncture that is usually asymptomatic and could be detected by $\mathrm{CT}$ incidentally. They can also be misinterpreted as osteolytic lesions in crosssectional imaging of the sternum.

The sternal cleft is a rare congenital defect of the anterior chest wall and is the result of a failed midline fusion of the sternum. The clinical significance is that it leaves the heart and great vessels unprotected [2]. In Yekeler's et al. study [30], manubrial cleft was depicted in $6(0.6 \%)$ subjects. All were in the superior portion of the manubrium and 5 (83.3\%) and were associated with a manubrial sclerotic band just inferior in relation to the cleft. Sternal cleft was located in the corpus and was detected in $8(0.8 \%)$ subjects; in all patients the clefts were found in the inferior part of the sternal body. In the present study, sternal clefts that were located in the manubrium were found in $0.5 \%$ subjects.

\section{CONCLUSIONS}

The sternum has various variations and anomalies. Multiplanar and curved-planar reconstructed MSCT images are useful in revealing sternal anatomy and describing sternal variations and anomalies. Awareness of MDCT appearances of sternal variations and anomalies provides a better differential diagnosis of pathologic conditions. We suggest that the morphometric standards cannot be universally applied and can demonstrate individual differences and the standard rules must be implemented for every population. Further studies on comparative samples may be helpful to determine the race or a particular population.

\section{REFERENCES}

1. Akin K, Kosehan D, Topcu A, et al. Anatomic evaluation of the xiphoid process with 64-row multidetector computed tomography. Skeletal Radiol. 2011; 40(4): 447-452, doi: 10.1007/s00256-010-1022-1, indexed in Pubmed: 20721551.

2. Aktan ZA, Savaş R. Anatomic and HRCT demonstration of midline sternal foramen. Tr J Med Sciences. 1998; 28: 511-514.

3. Ashley GT. The human sternum: the influence of sex and age on its measurements. J Forensic Med. 1956; 3: 27-43.

4. Babinski MA, de Lemos L, Babinski MSD, et al. Frequency of sternal foramen evaluated by MDCT: a minor variation of great relevance. Surg Radiol Anat. 2015; 37(3): 287-291, doi: 10.1007/s00276-014-1339-x, indexed in Pubmed: 25023390.

5. Babinski M, Rafael F, Steil A, et al. High prevalence of sternal foramen: quantitative, anatomical analysis and its clinical implications in acupuncture practice. Int $J$ Morphol. 2012; 30(3): 1042-1049, doi: 10.4067/s071795022012000300045 .

6. Bayaroğulları H, Yengil E, Davran R, et al. Evaluation of the postnatal development of the sternum and sternal variations using multidetector CT. Diagn Interv Radiol. 2014; 20(1): 82-89, doi: 10.5152/dir.2013.13121, indexed in Pubmed: 24100061.

7. Bongiovanni R, Spradley MK. Estimating sex of the human skeleton based on metrics of the sternum. Forensic Sci Int. 2012; 219(1-3): 290.e1-290.e7, doi: 10.1016/j. forsciint.2011.11.034, indexed in Pubmed: 22209293.

8. Cooper PD, Stewart JH, McCormick WF. Development and morphology of the sternal foramen. Am J Forensic Med Pathol. 1988; 9(4): 342-347, indexed in Pubmed: 3239556.

9. Dahiphale VP, Baheete BH, Kamkhedkar SG. Sexing the human sternum in Marathwada region. J Anat Soc India. 2002; 5: 162-167. 
10. Duraikannu C, Noronha OV, Sundarrajan P. MDCT evaluation of sternal variations: Pictorial essay. Indian J Radiol Imaging. 2016; 26(2): 185-194, doi: 10.4103/09713026.184407, indexed in Pubmed: 27413263.

11. Dwight T. Sternum as an index of sex, height, and age. J Anat Physiol. 1890; 24(Pt 4): 527-535, indexed in Pubmed: 17231878.

12. Dwight T. The sternum as an index of sex and age. J Anat Physiol. 1881; 15(Pt 3): 327-330, indexed in Pubmed: 17231387.

13. Fokin AA. Cleft sternum and sternal foramen. Chest Surg Clin N Am. 2000; 10(2): 261-276, indexed in Pubmed: 10803333.

14. Gkantsinikoudis N, Chaniotakis C, Gkasdaris G, et al. Morphological approach of the sternal foramen: an anatomic study and a short review of the literature. Folia Morphol. 2017; 76(3): 484-490, doi: 10.5603/FM.a2017.0006, indexed in Pubmed: 28150272.

15. Hunnargi SA, Menezes RG, Kanchan T, et al. Sexual dimorphism of the human sternum in a Maharashtrian population of India: a morphometric analysis. Leg Med. 2008; 10(1): 6-10, doi: 10.1016/j.legalmed.2007.05.011, indexed in Pubmed: 17698393.

16. Hyrtl J. Handbuch der topographischen anatomic percentage. Vienna: Wilhelm Braumuller. 1893; 1S: 348.

17. Işcan MY. Osteometric analysis of sexual dimorphism in the sternal end of the rib. J Forensic Sci. 1985; 30(4): 1090-1099, indexed in Pubmed: 4067537.

18. Jit I, Jhingan V, Kulkarni M. Sexing the human sternum. Am J Phys Anthropol. 1980; 53(2): 217-224, doi: 10.1002/ ajpa.1330530206, indexed in Pubmed: 7416254.

19. Moore MK, Stewart JH, McCormick WF. Anomalies of the human chest plate area. Radiographic findings in a large autopsy population. Am J Forensic Med Pathol. 1988; 9(4): 348-354, indexed in Pubmed: 3239557.

20. O'Neal ML, Dwornik JJ, Ganey TM, et al. Postnatal development of the human sternum. J Pediatr Orthop. 1998; 18(3): 398-405, indexed in Pubmed: 9600571.
21. Osunwoke EA, Gwunireama IU, Orish CN, et al. A study of sexual dimorphism of the human sternum in the southern Nigerian population. J Appl Biosci. 2010; 26: 1636-1639.

22. Paterson AM. The human sternum. Williams and Norgate, London: University Press of Liverpool. 1904; pp 36-37 and 77

23. Pevenage $P$, De Ma, Muylle $K$, et al. Sternal foramen simulating osteolytic lesion on scintigraphy and SPET imaging. Ann Nucl Med Sci. 2002; 15: 227-230.

24. Ramadan SU, Türkmen N, Dolgun NA, et al. Sex determination from measurements of the sternum and fourth rib using multislice computed tomography of the chest. Forensic Sci Int. 2010; 197(1-3): 120.e1-120. e5, doi: 10.1016/j.forsciint.2009.12.049, indexed in Pubmed: 20083365.

25. Rother $P$, Hunger $H$, Liebert $U$, et al. [Sex differences in the human sternum]. Gegenbaurs Morphol Jahrb. 1975; 121(1): 29-37, indexed in Pubmed: 1158101.

26. Selthofer R, Nikolić V, Mrcela T, et al. Morphometric analysis of the sternum. Coll Antropol. 2006; 30(1): 43-47, indexed in Pubmed: 16617574.

27. Teige K. [Morphometric studies of $x$-rays of the sternum]. Z Rechtsmed. 1983; 90(3): 199-204, indexed in Pubmed: 6624276.

28. Wenzel J (1788), cited by Ashley GT. A comparison of human and anthropoid mesosterna. Am J Phys Anthropol. 1956; 3: 449-65, indexed in Pubmed: 13381831.

29. Yamamura Y, Esper RS, Cricenti SV. Forames Esternais e Os Pontos de Acupuntura VC-17 (Shanzhong) e VC-16 (Zhongting) do canal curioso Ren Mai. Rev Paul Acupunt. 1996; 2(1): 29-33.

30. Yekeler $E$, Tunaci $M$, Tunaci $A$, et al. Frequency of sternal variations and anomalies evaluated by MDCT. AJR Am J Roentgenol. 2006; 186(4): 956-960, doi: 10.2214/ AJR.04.1779, indexed in Pubmed: 16554563. 